\title{
Strain Rate Dependent Mechanical Properties of TWIP Steel
}

\author{
MANJUNATHA MADIVALA $\oplus^{1,2}$ and WOLFGANG BLECK ${ }^{1}$ \\ 1.--Institut für Eisenhüttenkunde (IEHK), RWTH Aachen University, Intzestraße 1, 52072
}

Aachen, Germany. 2.—e-mail: mmadivala@iehk.rwth-aachen.de

\begin{abstract}
The effect of strain rate on the work-hardening behavior of high-manganese twinning-induced plasticity (TWIP) steel has been investigated. The influence of adiabatic heating and deformation rate on the mechanical properties was studied by quasi-static and dynamic tensile tests with synchronous temperature and strain measurements. TWIP steel has excellent strain-hardening behavior under both quasi-static and dynamic loading conditions. Strain rate has negligible effects on yield and tensile strength, but the uniform and total elongation decreases under dynamic tests. TWIP steel has excellent energy absorption (EA) capacity of above $55 \mathrm{~kJ} / \mathrm{kg}$ at all strain rates compared to dual-phase steels, transformation-induced plasticity steel and ferritic steels. However, the EA of TWIP steel is slightly lower compared to austenitic stainless steels. A rise in temperature due to adiabatic heating has led to the increase of stacking fault energy, thereby resulting in a change of twinning behavior or the promotion of dislocation glide under dynamic loading.
\end{abstract}

Key words: TWIP steel, AHSS, Strain rate, Dynamic tests, Energy absorption

\section{INTRODUCTION}

Many years of research and development have made advanced high-strength steels (AHSS) versatile and effective materials for the construction of structural parts in modern automobiles. The high demand for safety, durability and cost effectiveness has driven steel producers and engineers to develop new grades that are lighter, stronger and better formable with improved mechanical properties. ${ }^{1}$ These applications have ranged from increased strength for performance and weight reduction to zinc coatings for improved corrosion resistance to bake-hardenable grades for closure panel dent resistance. ${ }^{2}$ Steels for automotive applications in general require greater formability for styling body panels to great strength for crash performance. The components not only have to be stronger to resist crushing in the passenger compartment but should also provide energy absorption in the front and rear crumple zones. ${ }^{3}$ High-manganese twinning-induced plasticity (TWIP) steels are such a class of steels characterized by high work-hardening capacity along with exceptional strength and ductility. ${ }^{4-6}$ The high-energy absorption capacity enables their use in the production of high-performance structural parts in automobiles with superior crash performance and lightweight structural reinforcements. $^{7}$ To describe the overall performance of steels combining both strength and elongation, the most commonly used material characteristic parameter is the ECO-index, expressed as the product of ultimate tensile strength (UTS) and uniform elongation (UE). The ECO-index value for conventional AHSS is limited to about $20 \mathrm{GPa} \%$, but for high-Mn TWIP steels, it can go beyond $50 \mathrm{GPa} \% .{ }^{8}$ However, evaluating the material performance based solely on quasi-static tensile test properties, such as strength and ductility, and judging their suitability for structural parts may be inadequate since, during the crash of automobiles, the parts are not deformed until failure and the deformation rates are much larger. ${ }^{9}$ The most commonly used techniques to characterize dynamic tensile properties are the servo-hydraulic (SH) system, the split Hopkinson pressure bar (SHB) system, the single bar (SB) system and the drop weight system, with each test method providing a specific strain rate $(\dot{\varepsilon})$ range. The bar systems (SBH and SB) are able to offer very high $\dot{\varepsilon}$ range $(>1000 / \mathrm{s})$ compared with the $\mathrm{SH}$ 
system, yet the $\mathrm{SH}$ system is more reliable for relatively lower $\dot{\varepsilon}(<500 / \mathrm{s}) .{ }^{10}$ Thus, to check the crash-worthiness of TWIP steels, it is necessary to determine the mechanical properties and energy absorption capacity under dynamic loading conditions. In addition, it is also important to compare TWIP steel properties with other AHSS steel grades to check its suitability for different components.

The current study focuses on the influence of strain rate on the strain-hardening behavior of X60Mn22 TWIP steel. Uni-axial tensile tests were carried out at different strain rates ranging from $0.00001 / \mathrm{s}$ to $250 / \mathrm{s}$ to investigate the mechanical behavior under both quasi-static and dynamic conditions. Synchronous temperature measurements during deformation at various strain rates aid in the accurate estimation of stacking fault energy (SFE) at different strain rates, enabling the prediction of deformation mechanisms. The correlation of predicted deformation mechanisms with the mechanical behavior was also verified. Strain rate effect on the yield strength (YS), ultimate tensile strength (UTS), uniform elongation (UE), total elongation (TE) and energy absorption (EA) capacity of TWIP steel were compared with other AHSS, ferritic and austenitic stainless steels under both quasi-static and dynamic loading conditions. The temperature increase due to adiabatic heating and its subsequent effect on the mechanical properties at different strain rates has been presented in detail.

\section{MATERIAL AND EXPERIMENTAL METHODS}

\section{Material}

The material investigated in this study was industrially produced, cold-rolled and annealed sheet steel with a thickness of $1.4 \mathrm{~mm}$. The chemical composition of the alloy was determined by using optical emission spectroscopy, and the SFE of the material was calculated using the sub-regular solution thermodynamic model of Ref. 11, as described in Ref. 12, and both are shown in Table I. The interface energy $\left(\sigma^{\gamma / \varepsilon}\right)$ value of $10 \mathrm{~mJ} / \mathrm{m}^{2}$ was assumed for calculating the SFE.

The microstructure of the material consisted of fine equiaxed austenitic grains $(\gamma)$ with an average grain size of about $3.0 \mu \mathrm{m}$. Figure 1a shows the inverse pole figure (IPF) map with respect to the rolling direction, depicting the grain sizes and the crystal orientation distribution. Figure $1 \mathrm{~b}$ provides the grain size distribution function, where it can be observed that the grain size varied from $0.5 \mu \mathrm{m}$ to
$10 \mu \mathrm{m}$, with only a small fraction of grains being larger than $5 \mu \mathrm{m}$.

The materials used for the comparison of mechanical properties are mild steel DC04, high-strength steel ZStE340 with completely ferritic microstructure, dual-phase (DP) steels consisting of a dispersed martensite (M) in ferrite (F) matrix (DP600, DP800 and DP1000), transformation-induced plasticity (TRIP) steel consisting of ferrite, bainite and a small amount of retained austenite (A) and austenitic stainless steels (1.4301 and 1.4308) with fully austenitic microstructures. The grain size of DC04$22 \mu \mathrm{m}, \mathrm{ZStE} 340-7 \mu \mathrm{m}, \mathrm{DP} 600-5.5(\mathrm{~F})+4.1(\mathrm{M}) \mu \mathrm{m}$, DP800-4.4(F) + 4.0(M) $\mu \mathrm{m}, \mathrm{DP} 1000-2.8(\mathrm{~F})+2.0(\mathrm{M})$ $\mu \mathrm{m}$, TRIP-9.0(F) $+\mathrm{A}(<1.5) \mu \mathrm{m}, 1.4301-60 \mu \mathrm{m}$ and $1.4308-60 \mu \mathrm{m}$. All the investigated steels are industrially melted, hot- and cold-rolled, annealed and temper-rolled to a final sheet thickness between 1.0 and $2.0 \mathrm{~mm}$. More details about them can be found in Ref. 9. All the materials were tested in the asdelivered condition as explained in section "Mechanical Tests".

\section{Mechanical Tests}

Macroscopic tensile tests were carried out according to the DIN EN ISO 6892 standard with a specimen geometry consisting of a gage length of $20 \mathrm{~mm}$ and a width of $6 \mathrm{~mm}$, as shown in Fig. 2a. The samples for all the tests were obtained using water-jet cutting along the rolling direction. The cut edges of the samples were polished up to a surface roughness of $0.125 \mu \mathrm{m}$. Tensile tests in conjunction with a thermocamera were performed at room temperature (RT) using a Zwick/Roell Z100 tensile testing machine. To study the influence of $\dot{\varepsilon}$ under quasi-static loading, different cross-head displacement rates, such as $0.018 \mathrm{~mm} / \mathrm{min}, 0.18 \mathrm{~mm} / \mathrm{min}$, $1.8 \mathrm{~mm} / \mathrm{min}, \quad 18 \mathrm{~mm} / \mathrm{min}, \quad 180 \mathrm{~mm} / \mathrm{min}$ and $900 \mathrm{~mm} / \mathrm{min}$, were set to achieve the strain rates of $0.00001 / \mathrm{s}, 0.0001 / \mathrm{s}, 0.001 / \mathrm{s}, 0.01 / \mathrm{s}, 0.1 / \mathrm{s}$ and $0.5 / \mathrm{s}$, respectively. A video-extensometer was used to measure the change in length of the samples, which facilitates the recording of the actual elongation. Young's modulus, shear modulus and Poisson's ratio of the material were determined by an ultrasonic method, as described in Ref. 13.

To investigate the TWIP steel behavior under crash loading conditions, dynamic tensile tests were carried out at RT using a servo-hydraulic highspeed Roell/Amsler HTM2012 tensile testing machine equipped with an electro-optical extensometer and a thermocamera. Tensile tests with the

Table I. Chemical composition (in wt.\%) and the SFE value (in $\mathrm{mJ} / \mathrm{m}^{2}$ ) of the investigated TWIP steel

\begin{tabular}{|c|c|c|c|c|c|c|c|c|c|c|c|c|}
\hline $\mathbf{C}$ & $\mathbf{S i}$ & Mn & $\mathbf{P}$ & $\mathbf{S}$ & $\mathbf{C r}$ & $\mathbf{N i}$ & $\mathbf{C u}$ & Al & $\mathbf{V}$ & $\mathbf{N}$ & $\mathbf{F e}$ & SFE \\
\hline 0.59 & 0.21 & 22.26 & 0.013 & $<0.001$ & 0.08 & 0.02 & 0.02 & 0.01 & 0.27 & 0.019 & Bal. & 27 \\
\hline
\end{tabular}


(a) EBSD inverse pole figure (IPF) map

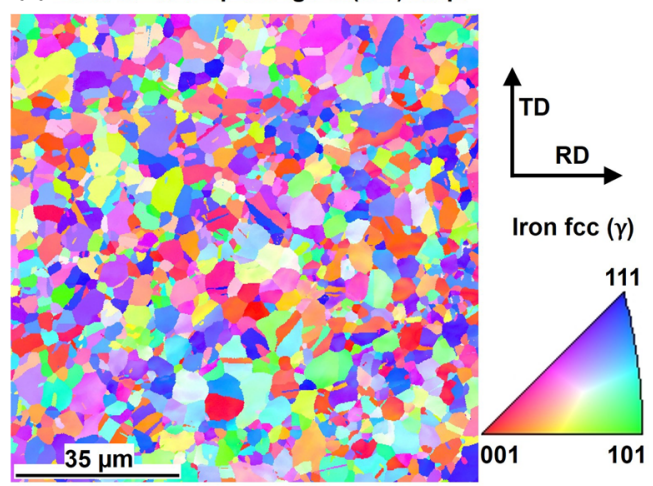

(b) Grain size distribution

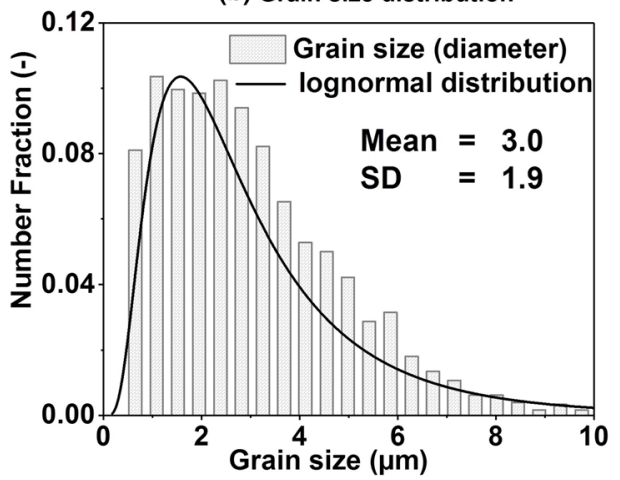

Fig. 1. Microstructure and grain size distribution of the investigated TWIP steel. (a) EBSD IPF map of undeformed sample showing variation in grain size and orientation; microstructure is fully austenitic $(\gamma) ; R D$ rolling direction; $T D$ transverse direction. (b) Grain size distribution obtained from EBSD measurements fitted with a log-normal distribution function; average grain size is $3.0 \mu \mathrm{m}$ and standard deviation $(S D)$ is $1.9 \mu \mathrm{m}$.

(a) Quasi-static tensile tests specimen

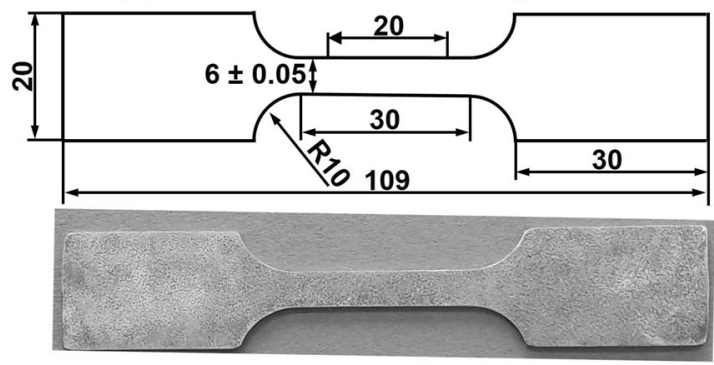

Thickness of sheet $=1.4 \mathrm{~mm}$ (b) Dynamic tensile tests specimen

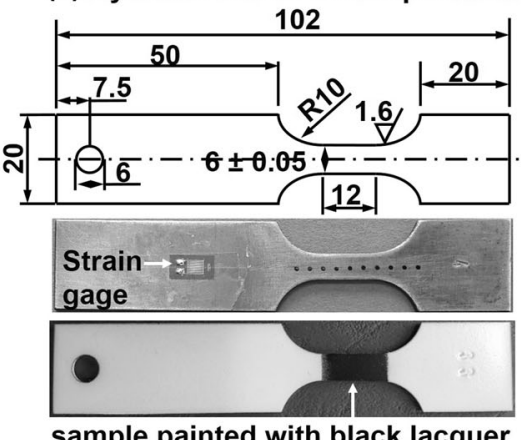

Fig. 2. Geometries used for the quasi-static and dynamic tensile tests.

ram speeds in the range from $0.01 \mathrm{~mm} / \mathrm{s}$ to $5000 \mathrm{~mm} / \mathrm{s}$ can be performed with the geometry shown in Fig. 2b. The speeds used in the current work were $12 \mathrm{~mm} / \mathrm{s}, 120 \mathrm{~mm} / \mathrm{s}, 1200 \mathrm{~mm} / \mathrm{s}$ and $3000 \mathrm{~mm} / \mathrm{s}$, which correspond to the strain rates of $1 / \mathrm{s}, 10 / \mathrm{s}, 100 / \mathrm{s}$ and $250 / \mathrm{s}$, respectively. The tensile force was measured by a standard piezo-electric load cell up to a $\dot{\varepsilon}$ of $10 / \mathrm{s}$, and at high strain rates using a titanium load cell with strain gages attached to the sample shoulder (as shown in the middle of Fig. 2b). The strain was measured by an inductive displacement sensor for the piston stroke, and the results were verified by using an electro-optical extensometer. The storage of test data was carried out using a 4-channel transient recorder. The sample was painted with black lacquer to achieve the optimum contrast for the elongation measurements using an extensometer of type Zimmer $200 \times$.

Temperature variation in the specimen during deformation was investigated by carrying out tensile tests in conjunction with a high-speed infrared thermography camera (JADE III MWIR S MTC; InfraTec). A sample geometry shown in Fig. 2b was used for all tests. A Zwick/Roell Z100 machine was used for the quasi-static tests and Roell/Amsler HTM2012 for the dynamic tests. Each specimen was coated with a black lacquer to minimize the reflections from the surroundings. The temperature measurement range of the camera is from $-40^{\circ} \mathrm{C}$ to $600^{\circ} \mathrm{C}$. The temperature measurement was carried out as a function of strain rate and maximum image acquisition rate in different photography modes. The data was acquired and analyzed using IRBIS $^{\circledR}$ online software to extract the temperature variation within the gage length of the specimen. The temperature data were correlated with the strain measured from the extensometer. For all the quasi-static tests, images were acquired at a frame rate of $1 \mathrm{~Hz}$ in full-frame-mode with a maximum of $384 \times 288$ pixels and with a temperature calibration range from $30^{\circ} \mathrm{C}$ to $130^{\circ} \mathrm{C}$. At the strain rates of $1 / \mathrm{s}$ and $10 / \mathrm{s}$, images were acquired in quarterframe-mode at a frame rate of $888 \mathrm{~Hz}$ with a maximum of $80 \times 60$ pixels and a calibration range from $30^{\circ} \mathrm{C}$ to $170^{\circ} \mathrm{C}$. For strain rates above $10 / \mathrm{s}$, images were captured using line-mode at a frame rate of $6578 \mathrm{~Hz}$ with a maximum of $320 \times 1$ pixels and a calibration range from $30^{\circ} \mathrm{C}$ to $150^{\circ} \mathrm{C}$. The major difference between line-mode and the others is that only a single line in the center of the sample over the entire gage length will be scanned during deformation, whereas full/half/quarter images will 
be captured in the other modes. The overall accuracy of the temperature measurements within the range of calibration was $\pm 1^{\circ} \mathrm{C}$.

\section{RESULTS}

The strain rate-dependent properties of TWIP steel are of crucial importance for evaluating the crash performance of the material, and they also play a large role in selecting the optimal forming processes for the manufacturing of components. Understanding the mechanical behavior under both quasi-static and dynamic conditions will aid in choosing TWIP steel for a particular application.

\section{Mechanical Properties}

The $\sigma-\varepsilon$ curves and the strain-hardening rate (SHR) obtained by uni-axial tensile tests at RT at different $\dot{\varepsilon}$ are shown in Fig. 3, where periodic serrations of type A can be observed, caused mainly by dynamic strain aging (DSA). At a $\dot{\varepsilon}$ of $0.001 / \mathrm{s}$, the material shows almost linear flow behavior throughout the deformation and an abrupt failure at the end. Initially, hardening is characterized by a sharp drop of the SHR, which then increases to reach a constant value with small increase in deformation. The first marked inflexion in SHR occurs at $\sim 0.05$ true strain, where it started to decrease steadily. Thereafter, SHR shows a general drop until the final failure, indicating no additional active deformation mechanisms. The SHR at the beginning of the deformation for a $\dot{\varepsilon}$ of $0.001 / \mathrm{s}$ is above $3000 \mathrm{MPa}$, and it decreases to about 2000 $\mathrm{MPa}$ at failure.

The mechanical properties of TWIP steel, such as YS, UTS, UE, TE, Lankford coefficient ( $r$-value), strain hardening exponent ( $n$-value), density $(\rho)$, Young's modulus $(E)$, shear modulus $(G)$, Poisson's ratio $(v)$ and ECO-index tested at a $\dot{\varepsilon}$ of $0.001 / \mathrm{s}$, are presented in Table II. The material has a YS of 500 $\mathrm{MPa}$ along RD and a UTS of above $1100 \mathrm{MPa}$. TE or the macroscopic failure strain $\left(\varepsilon_{\mathrm{f}}\right)$ of the material is about $45 \%$. The ECO-index of TWIP steel is about $52 \mathrm{GPa} \%$ and the strain-hardening exponent $(n-$ value) is $\sim 0.33$. The material has a Young's modulus of $165 \mathrm{GPa}$, shear modulus of $63 \mathrm{GPa}$ and a Poisson's ratio of 0.31 .

\section{Effect of Strain Rate}

The $\sigma-\varepsilon$ curves of quasi-static and dynamic tensile tests are shown in Fig. 3a and c. Serrations can be observed on the $\sigma-\varepsilon$ curves depicted in Fig. 3 a for all $\dot{\varepsilon}$ except at $0.5 / \mathrm{s}$. With an increase in $\dot{\varepsilon}$ from $0.00001 /$ $\mathrm{s}$ to $0.5 / \mathrm{s}$, the serrations start to disappear and the failure behavior changes from abrupt failure to necking and failure. Under the dynamic loading conditions, as shown in Fig. 3c, smooth flow behavior without any serrations can be observed along with the pronounced necking and failure at the end. The serrations observed on the $\sigma-\varepsilon$ curves for $\dot{\varepsilon}$ of 100/s and 250/s in Fig. 3c are not due to DSA, but mainly due to the force measurement.

The SHR $(\mathrm{d} \sigma / \mathrm{d} \varepsilon)$ plotted as a function of quasistatic and dynamic $\dot{\varepsilon}$ are shown in Fig. 3 b and d, respectively. The hardening for all $\dot{\varepsilon}$ is characterized by a sharp drop in the SHR, followed by its increase to a constant value with further increase in deformation. The first inflexion in SHR occurs at $\sim 0.05$ true strain for a $\dot{\varepsilon}$ of $0.00001 / \mathrm{s}$ and it shifts to the right with increasing $\dot{\varepsilon}$. The inflexion in SHR for $\dot{\varepsilon}$ above $0.5 / \mathrm{s}$ occurs at $\sim 0.1$ true strain, where it started to decrease steadily. The SHR for a $\dot{\varepsilon}$ of $0.00001 / \mathrm{s}$ is about $3500 \mathrm{MPa}$ at the beginning of the deformation and decreases to about $2000 \mathrm{MPa}$ at failure. With the increase in $\dot{\varepsilon}$ from $0.00001 / \mathrm{s}$ to $0.5 /$ $\mathrm{s}$, the SHR decreases from $3500 \mathrm{MPa}$ to $2800 \mathrm{MPa}$ at the beginning of the deformation. The SHR of TWIP steel decreases with increasing $\dot{\varepsilon}$ and shows a general drop for all quasi-static tests until the final failure, indicating no additional active deformation mechanisms. The SHR is above $2500 \mathrm{MPa}$ for all dynamic tests up to a true strain of $\sim 0.2$. With further increase in deformation, the SHR decreases steadily for all dynamic tests, suggesting a slight change in the deformation behavior of the material.

The variation of mechanical properties with increasing $\dot{\varepsilon}$ is plotted in Fig. 3e. The YS of the material remains almost constant for all quasistatic tests, and starts to increase linearly when the $\dot{\varepsilon}$ changed to dynamic. The UTS of the material is above $1000 \mathrm{MPa}$ until a $\dot{\varepsilon}$ of $0.5 / \mathrm{s}$, and it started to decrease slightly by about $50 \mathrm{MPa}$ with the further increase in $\dot{\varepsilon}$. The uniform/total elongation (UE/TE) of the material is almost the same for the quasistatic tests, but with increasing $\dot{\varepsilon}$, the UE decreased almost linearly, whereas the TE is almost constant at high $\dot{\varepsilon}$ as well.

The strain rate influence on the YS, UTS and UE/ TE of TWIP steel compared with other steels [AHSS (DP steels and TRIP steel), austenitic stainless steel (1.4301) and ferritic steels (mild steel-DC04 and extra deep drawable steel-ZStE340)] is shown in Fig. 4. The results show significant strain rate dependencies for TWIP steel and also for all other steels considered for comparison. The YS of all steels increase continuously with increasing $\dot{\varepsilon}$, as shown in Fig. 4a; however, TWIP and TRIP steels have smaller slopes compared to ferritic, DP steels and austenitic stainless steel. Strain rate has a remarkable effect on YS in DP steels, where YS increases drastically for DP1000 and marginally for DP600 and DP800 with increasing $\dot{\varepsilon}$. The UTS of TWIP steel decreases slightly with increasing $\dot{\varepsilon}$ compared to increases in UTS in all other steels, as plotted in Fig. 4b. The increase in tensile strength is smaller in the cases of DP1000 and TRIP steel, whereas in other steels the effect is more substantial. The UE of the TWIP steel decreases with increasing $\dot{\varepsilon}$ similar to ferritic steels, as shown in Fig. 4c. The austenitic stainless steel, DP600 and DP800 show slight decreases in UE initially and 
(a) Stress-strain curves of quasi-static tensile tests

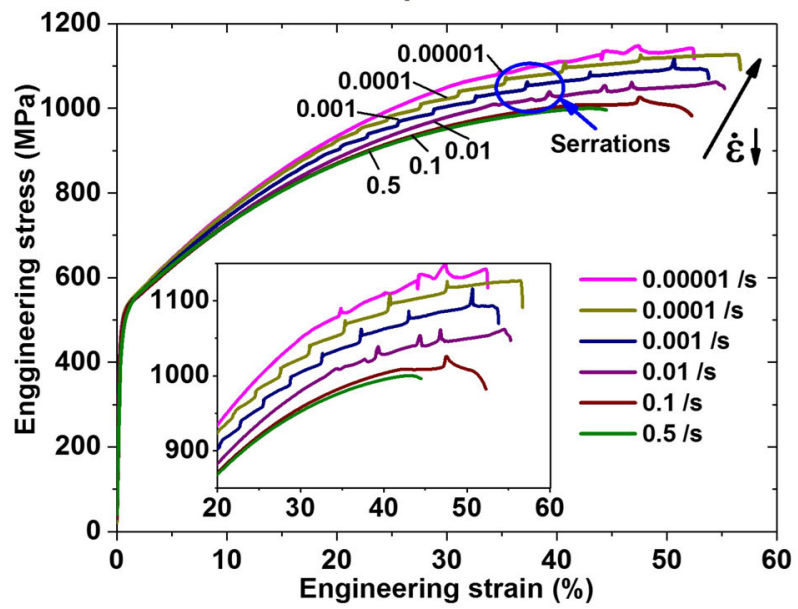

(c) Stress-strain curves of dynamic tensile tests

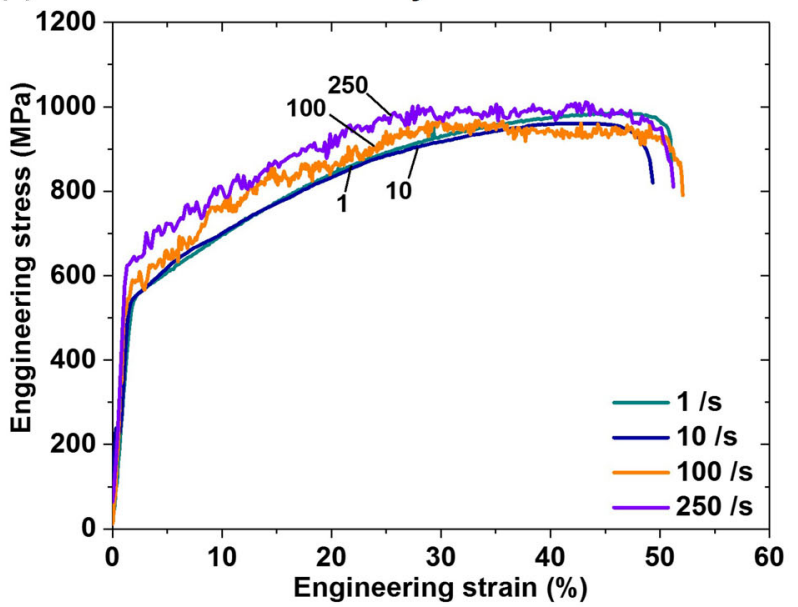

(b) Strain hardening behavior under quasi-static loading

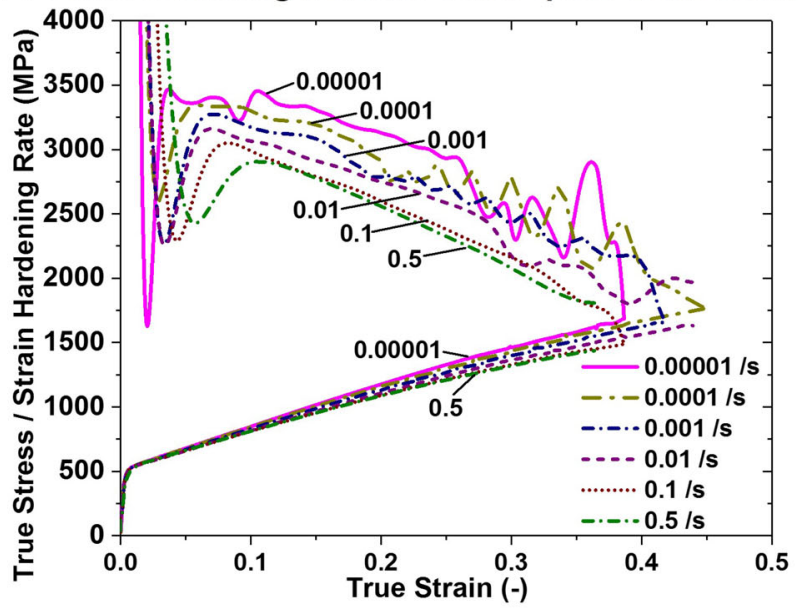

(d) Strain hardening behavior under dynamic loading

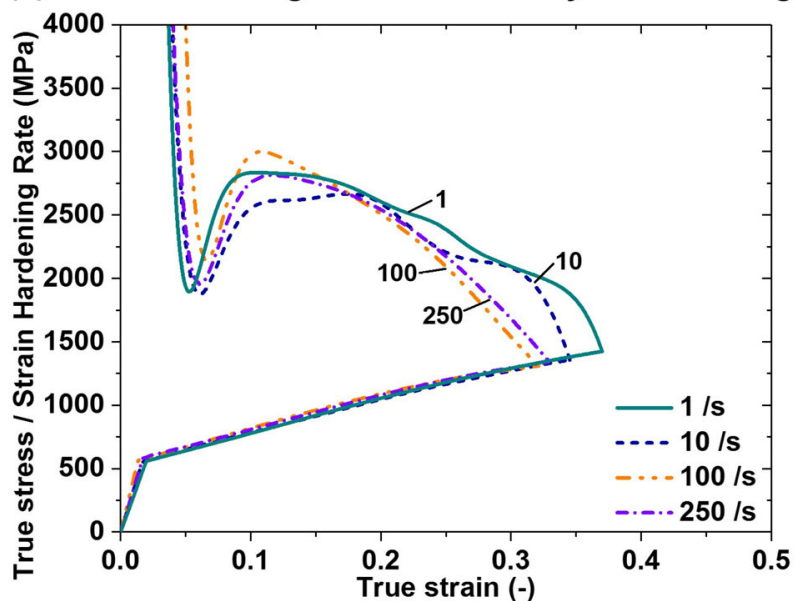

(e) Mechanical properties as a function of strain rate during tensile testing

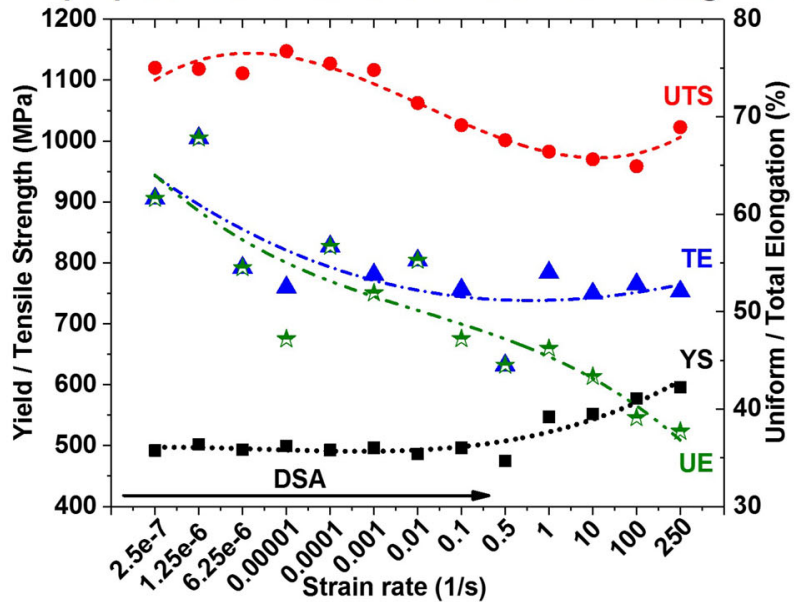

Fig. 3. Strain rate effect on the mechanical properties. The strain-hardening curves are smoothened for strain rates of $100 / \mathrm{s}$ and $250 / \mathrm{s}$. YS yield strength, UTS ultimate tensile strength, UE uniform elongation, TE total elongation.

thereafter increases for very high $\dot{\varepsilon}$. Strain rate has a negligible effect on the UE of TRIP steel and DP1000. From Fig. 4d, it can be observed that the TE values of TWIP steel, austenitic stainless steel and TRIP steel first decrease up to moderate strain rates followed by an increase up to the highest strain rates, obtaining the same values as measured under quasi-static conditions. The TE of ferritic 
Table II. Mechanical properties of X60Mn22 TWIP steel: yield/ultimate tensile strength (YS/UTS), uniform/total elongation (UE/TE), Lankford coefficient ( $r$ value), strain hardening exponent ( $n$ value), Young's modulus $(E)$, shear modulus $(G)$, Poisson's ratio $(v)$ and ECO-index

\begin{tabular}{|c|c|c|c|c|c|c|c|c|c|c|}
\hline Direction & $\begin{array}{c}\text { YS } \\
\text { MPa } \\
\end{array}$ & $\begin{array}{l}\text { UTS } \\
\text { MPa }\end{array}$ & $\begin{array}{c}\text { UE } \\
\% \\
\end{array}$ & $\underset{\%}{\mathbf{T E}}$ & $\begin{array}{c}\boldsymbol{r} \text { value } \\
-\end{array}$ & $\begin{array}{c}n \text { value } \\
-\end{array}$ & $\begin{array}{c}\mathbf{E} \\
\mathbf{G P a}\end{array}$ & $\begin{array}{c}\mathbf{G} \\
\mathbf{G P a}\end{array}$ & $\begin{array}{l}v \\
-\end{array}$ & $\begin{array}{c}\text { ECO-index } \\
\text { GPa \% }\end{array}$ \\
\hline $\mathrm{RD}$ & 501 & 1139 & 45.7 & 45.7 & 0.81 & 0.33 & 165.7 & 62.9 & 0.316 & 52 \\
\hline
\end{tabular}

All data are average values determined from at least three parallel experiments. $R D$ rolling direction.

(a) Strain rate effect on YS

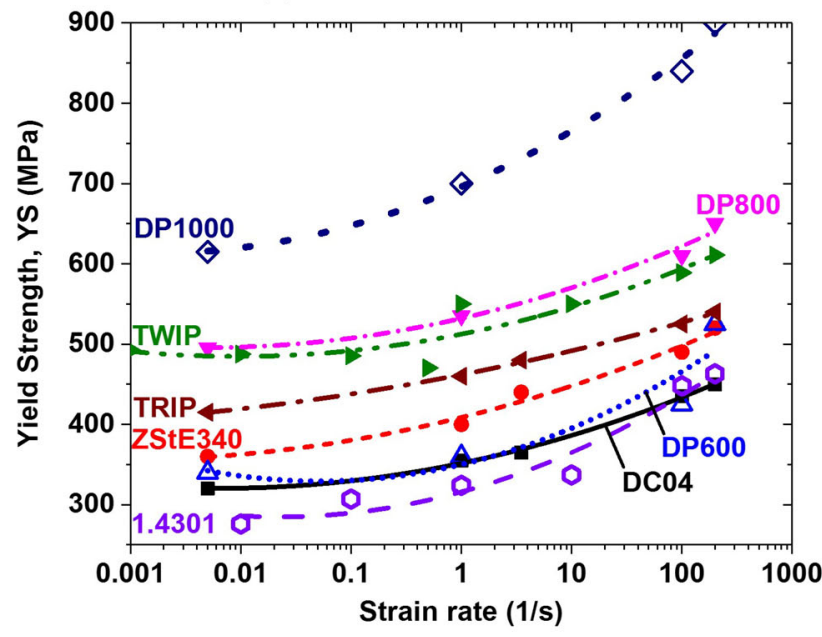

(c) Strain rate effect on UE

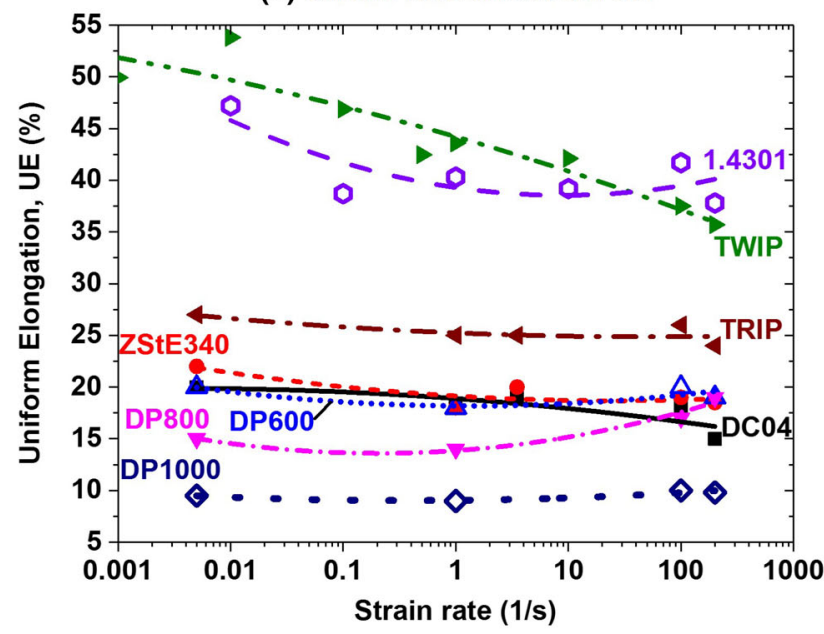

(b) Strain rate effect on UTS

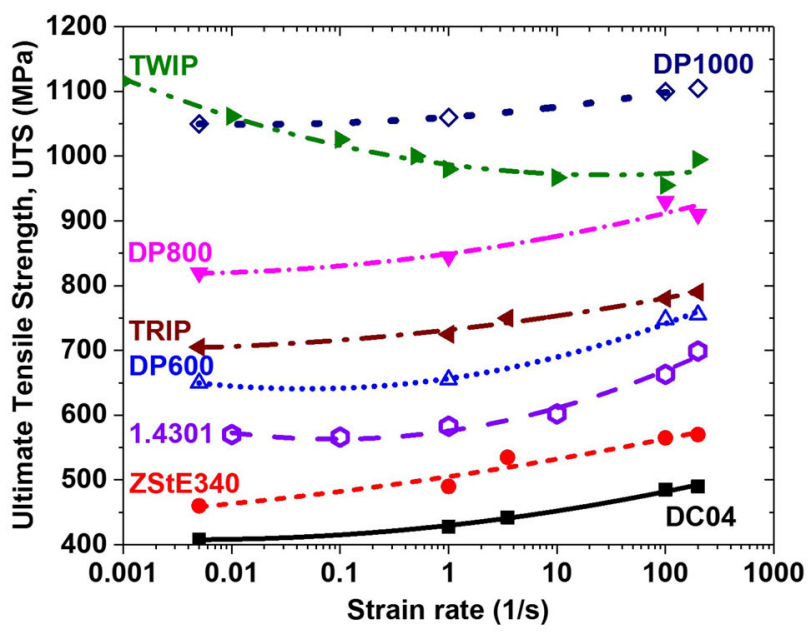

(d) Strain rate effect on TE

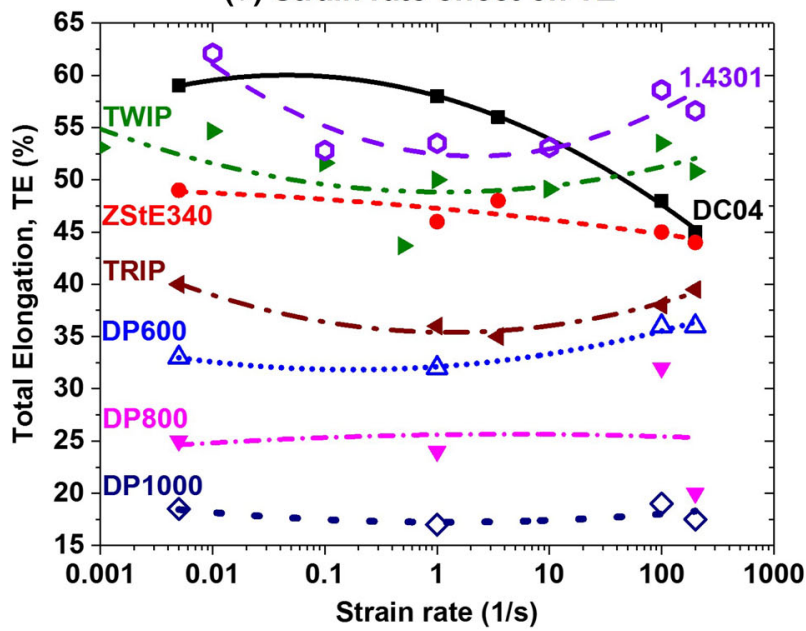

Fig. 4. Comparison of the mechanical properties of TWIP steel with other advanced high strength steels (AHSS) and conventional steels. The mechanical properties data for ferritic steels, DP steels and TRIP steel were taken from Ref. 9. The data for austenitic stainless steel 1.4301 were taken from Ref. 14. All data are average values determined from at least three repeated experiments.

steels also decreases with increasing $\dot{\varepsilon}$, similar to the UE, as illustrated in Fig. 4c.

The strain rate effect on UTS, UE and TE is negligible for TRIP and DP1000, whereas the YS increase in DP1000 is fairly large compared to TRIP steel. In the case of TWIP steel, the strain rate effect on YS, UTS and TE is marginal compared to the huge influence on UE. The strain rate dependency of the elongation values, shown in Fig. 4c and $d$, indicate the largest difference between UE and TE for ferritic steels, whereas for all other steels both the elongation values were found to be similar. The ferritic steels DC04 and ZStE340, show decreases in elongation values over the whole range of $\dot{\varepsilon}$, whereas 
the ductility of 1.4301, TWIP, TRIP and DP600 steels is minimum at intermediate $\dot{\varepsilon}$. The elongation values at high strain rates are almost the same or even higher as those of quasi-static conditions. This behavior of the materials can be correlated to local temperature increases in the specimens due to adiabatic heating.

The local temperature increase in the material during deformation due to adiabatic heating is shown in Fig. 5. For tensile tests at different $\dot{\varepsilon}$, the temperature distribution over the entire gage length of the specimen with increasing strain is shown in Fig. 5a, and the temperature variation in the middle of the specimen is shown in Fig. 5b. It can be observed from Fig. 5a that, with the increase in macroscopic strain, the temperature in the specimen rises due to adiabatic heating. As the $\dot{\varepsilon}$ increases from quasi-static to dynamic, the temperature raises quite rapidly in the specimen during deformation. The localized deformation in the material after reaching uniform elongation will also lead to a rise in temperature locally. At the $\dot{\varepsilon}$ of $0.01 / \mathrm{s}$ and $0.5 / \mathrm{s}$, the maximum localized temperature

(a) Temperature measurement during deformation on the specimen surface using thermocamera

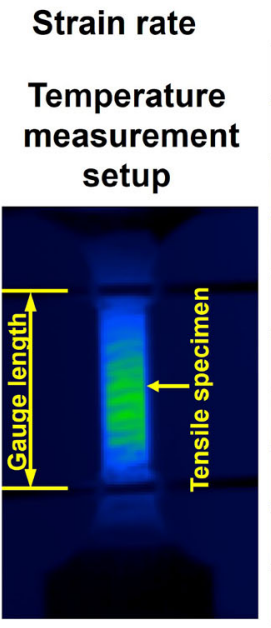

\begin{tabular}{|l|}
\multicolumn{2}{|c|}{$0.01 / \mathrm{s}$} \\
\hline$\sim 3 \%$ \\
\hline$\sim 10 \%$ \\
\hline $20 \%$ \\
\hline$\sim 30 \%$ \\
\hline$\sim 40 \%$ \\
\hline$\sim 45 \%$ \\
\hline$\sim 46 \%$ \\
\hline$\sim 47 \%$ \\
\hline$\sim 48 \%$ \\
\hline$\sim 49 \%$ \\
\hline
\end{tabular}

\begin{tabular}{|l|}
\hline \multicolumn{2}{|c|}{$0.5 / \mathbf{s}$} \\
\hline$\sim 5 \%$ \\
\hline$\sim 7.5 \%$ \\
\hline$\sim 10 \%$ \\
\hline$\sim 15 \%$ \\
\hline$\sim 20 \%$ \\
\hline$\sim 25 \%$ \\
\hline$\sim 35 \%$ \\
\hline$\sim 37 \%$ \\
\hline$\sim 40 \%$ \\
\hline
\end{tabular}

\begin{tabular}{|l|}
\hline \multicolumn{1}{l|}{$1 / \mathrm{s}$} \\
\hline$\sim 3 \%$ \\
\hline$\sim 10 \%$ \\
\hline$\sim 15 \%$ \\
\hline$\sim 30 \%$ \\
\hline$\sim 35 \%$ \\
\hline$\sim 40 \%$ \\
\hline$\sim 45 \%$ \\
\hline$\sim 47 \%$ \\
\hline$\sim 50 \%$ \\
\hline$-55 \%$ \\
\hline
\end{tabular}

\begin{tabular}{|l|l|}
\hline$\sim 3 \%$ & $10 / \mathbf{S}$ \\
\hline$\sim 10 \%$ & \\
\hline$\sim 15 \%$ & 150 \\
\hline$\sim 30 \%$ & ${ }^{\circ} \mathrm{C}-$ \\
\hline$\sim 35 \%$ & 100 \\
\hline$\sim 40 \%$ & \\
\hline$\sim 45 \%$ & \\
\hline$\sim 50 \%$ & 50 \\
\hline$\sim 52 \%$ & \\
\hline$\sim 54 \%$ & \\
\hline
\end{tabular}

(b) Temperature variations in specimen at different strain rates and elongations
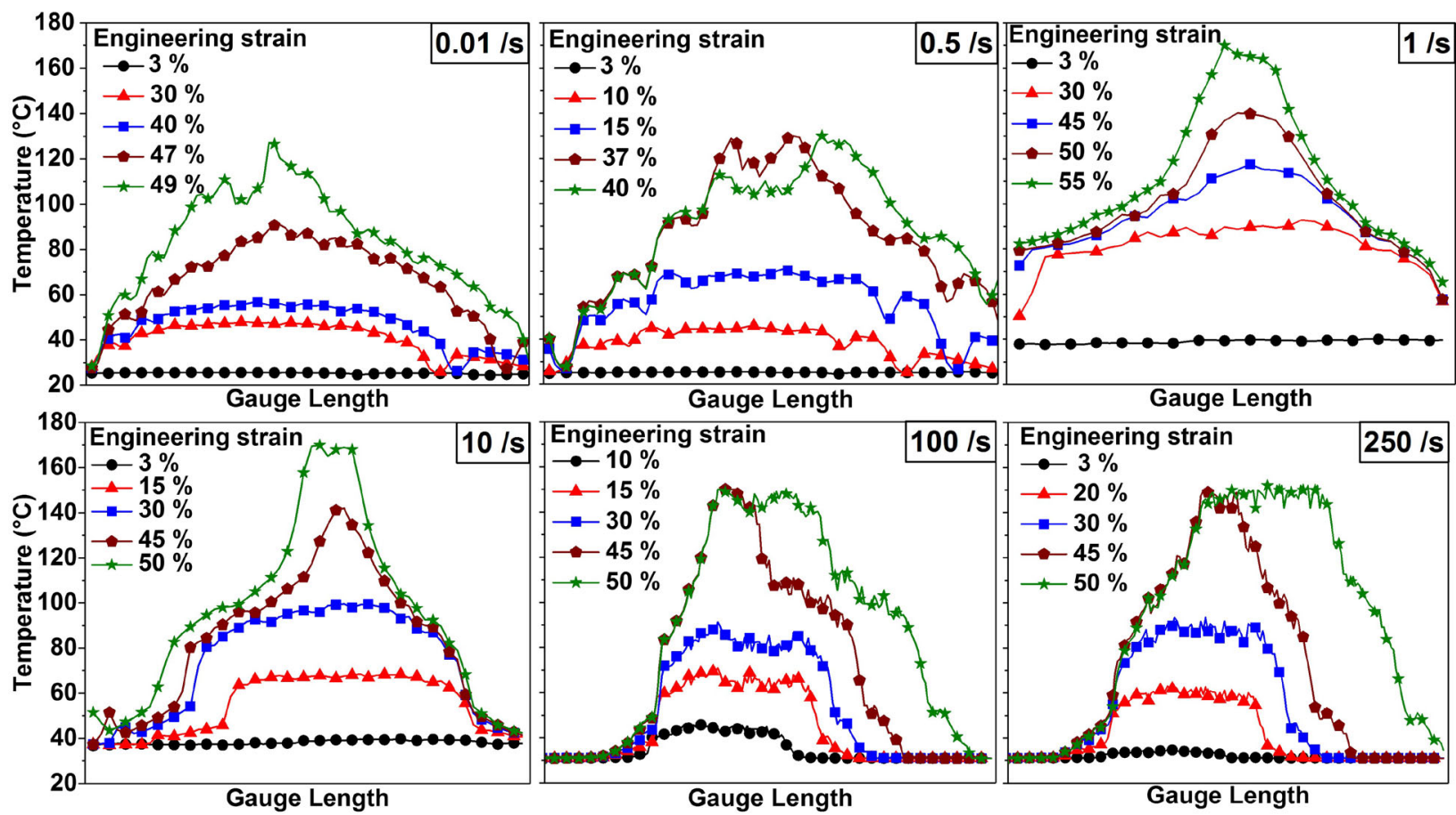

Fig. 5. Strain rate influence on the adiabatic heating during deformation. (a) Left measurement setup illustration; middle temperature distribution at different strain rates and macroscopic strains over the entire gage length; right legend for local temperature distribution. (b) Thermocamera temperature calibration range: from $30-130^{\circ} \mathrm{C}$ for strain rates of $0.01 / \mathrm{s}$ and $0.5 / \mathrm{s}$; from $30-170^{\circ} \mathrm{C}$ for $1 / \mathrm{s}$ and $10 / \mathrm{s}$; from $30-150^{\circ} \mathrm{C}$ for $100 / \mathrm{s}$ and $250 / s$. 
just before the failure is $\sim 120^{\circ} \mathrm{C}$, whereas under dynamic tests, the temperature rises even higher to $\sim 180^{\circ} \mathrm{C}$ and above. However, at the point before the uniform elongation, the average temperature is between $60^{\circ} \mathrm{C}$ and $100^{\circ} \mathrm{C}$. At $\sim 30 \%$ strain, the temperature distribution in the specimen is uniform throughout and the average values are about $40^{\circ} \mathrm{C}$, $80^{\circ} \mathrm{C}, 90^{\circ} \mathrm{C}, 100^{\circ} \mathrm{C}$, and $110^{\circ} \mathrm{C}$ at a $\dot{\varepsilon}$ of $0.01 / \mathrm{s}, 0.5 / \mathrm{s}, 1 / \mathrm{s}$, $10 / \mathrm{s}$ and $100 / \mathrm{s}$, respectively. After $30 \%$ strain, the temperature distribution is localized and increases further close to necking. Just before failure, the temperature raises above $200^{\circ} \mathrm{C}$ locally, which is also beyond the range of temperature measurements in high-speed testing. It can be seen from Fig. $5 \mathrm{~b}$ that, as the $\dot{\varepsilon}$ is increased from quasi-static to dynamic, localization of the temperature increases due to necking at high $\dot{\varepsilon}$, whereas the temperature distribution is more uniform over the gage length until failure at low $\dot{\varepsilon}$. The rise in temperature above $180^{\circ} \mathrm{C}$ due to adiabatic heating could influence the deformation mechanisms active at different $\dot{\varepsilon}$, leading to change in the material failure behavior.

\section{Energy Absorption}

The important property which characterize the crash behavior of the material is the specific energy absorption (EA), defined as the deformation energy per unit volume at a given temperature $\left(23^{\circ} \mathrm{C}\right)$ and at the $\dot{\varepsilon}$ of $100 / \mathrm{s}$ to $1000 / \mathrm{s}$, determined by high-speed tensile tests. Similarly, ECO-index parameter defined as the product of UTS and UE is also an indicator of the overall performance of the material.

Energy absorption values for different steels are determined by integrating the area under the $\sigma-\varepsilon$ curve until the start of the decrease in stress, as shown in Fig. 6a, and alternatively until $10 \%$ elongation. The area under the $\sigma-\varepsilon$ curve for TWIP steel is quite large compared with all other AHSS, indicating high energy absorbed per volume (W). In order to exclude the influence of the specimen geometry, particularly the different thickness values, the total energy values were converted to massspecific values. The bar diagram in Fig. $6 c$ shows the total specific EA capacity of the TWIP steel in comparison with other AHSS (DP steels and TRIP steel), ferritic steels (DC04 and ZStE340) and austenitic stainless steels (1.4301 and 1.4318). ${ }^{9} \mathrm{EA}$ values of TWIP steel are double or even higher than those of DP steels (DP600, DP800 and DP1000) and ferritic steels. TWIP steel absorbs 1.5 times more energy than that of the TRIP steel and also more than twice that of DP1000 at all $\dot{\varepsilon}$. However, both austenitic stainless steels (1.4301 and 1.4318) show slightly higher EA compared to TWIP steel under crash conditions. At a $\dot{\varepsilon}$ above $100 /$ s, specific EA values of TWIP steels are above $55 \mathrm{~kJ} / \mathrm{kg}$ and all other AHSS and ferritic steels possess energy values between $22 \leq \mathrm{W} \leq 35 \mathrm{~kJ} / \mathrm{kg}$, which absorb $60-35 \%$ less energy compared to that of the crash-resistant TWIP steel.
Higher EA is achieved by the TWIP steel for all $\dot{\varepsilon}$. However, the absorption is slightly lower for the dynamic tests, since there is a sharp drop in UTS and UE with increasing $\dot{\varepsilon}$. Similarly, TRIP steel also absorbs high energy for all $\dot{\varepsilon}$, but the absorption is maximum for the dynamic tensile tests $(\dot{\varepsilon}=100 / \mathrm{s}$ or 250/s), since the YS and UTS increases with increasing $\dot{\varepsilon}$ with no significant effect on the UE. The energy values of austenitic stainless steels are nearly twice that of TRIP steel and also slightly higher than that of TWIP steel. The EA is even higher ( $\sim$ thrice) when compared to ferritic and DP steels. At a $\dot{\varepsilon}$ of $200 / \mathrm{s}$, the energy values of TRIP steel are 1.5 times that of DP800, DP1000 and slightly higher compared to DP600. At $\dot{\varepsilon}=200 / \mathrm{s}$, EA values of DP600 are high compared to DP800, DP1000 and also ferritic steels. At lower $\dot{\varepsilon}$ up to $1 /$ $\mathrm{s}$, EA values are similar for all DP steels. DP800 shows high energy only at $100 / \mathrm{s}$, whereas at all other $\dot{\varepsilon}, \mathrm{EA}$ is less and also lower values at higher $\dot{\varepsilon}$. Similar trends can also be seen in DP1000. The EA of DC04 is nearly constant for all $\dot{\varepsilon}$ because the decrease in UE/TE is compensated by the increase in YS/UTS. Energy values are similar for ZStE340 in quasi-static tests, but show increased values for dynamic tests, since the ductility decrease with increasing $\dot{\varepsilon}$ is smaller.

It can be understood from Figs. $6 \mathrm{c}$ and $4 \mathrm{c}$, that for all steels the change in EA at different $\dot{\varepsilon}$ is mainly influenced by elongation values. Considering the fact that parts subjected to crash loading will never be deformed until failure, it is reasonable to compare EA values of steels up to $10 \%$ elongation. This procedure also eliminates the adiabatic heating effects and also statistical errors arising in estimating elongation values. Figure $6 \mathrm{~d}$ shows the EA comparison up to $10 \%$ elongation. It can be observed that TWIP steel absorbs more energy compared to all other AHSS and ferritic steels for up to $10 \%$ elongation. However, the austenitic stainless steels still absorbs more energy compared to all other steels considered for the comparison. Total EA of DP800 and DP1000 under crash conditions $(\dot{\varepsilon}=100 /$ s) is less than that of DP600 and TRIP steel, whereas for up to $10 \%$ elongation they both absorb more energy compared to DP600 and TRIP steel. The EA values for TRIP steel are higher even if the value at $\dot{\varepsilon}=100 / \mathrm{s}$ is slightly lower than that of DP800 and DP1000. EA values for ferritic steels look almost similar to the behavior shown in Fig. 6c, especially for ZStE340, whereas for DC04 the values increases slightly with increasing $\dot{\varepsilon}$, but the energy values are still lowest compared to all other steels considered.

Figure $6 \mathrm{~b}$ shows the comparison of the ECO-index of TWIP steel with other AHSS and conventional steels. It is shown in the diagram that the ECOindex of TWIP steel decreases from $\sim 55 \mathrm{GPa} \%$ to $\sim 35 \mathrm{GPa} \%$, when $\dot{\varepsilon}$ changed from quasi-static to dynamic. The ECO-index of TWIP steel is above 35 $\mathrm{GPa} \%$ for all $\dot{\varepsilon}$, whereas for all other steel grades, 
(a) Schematics of energy absorption estimation

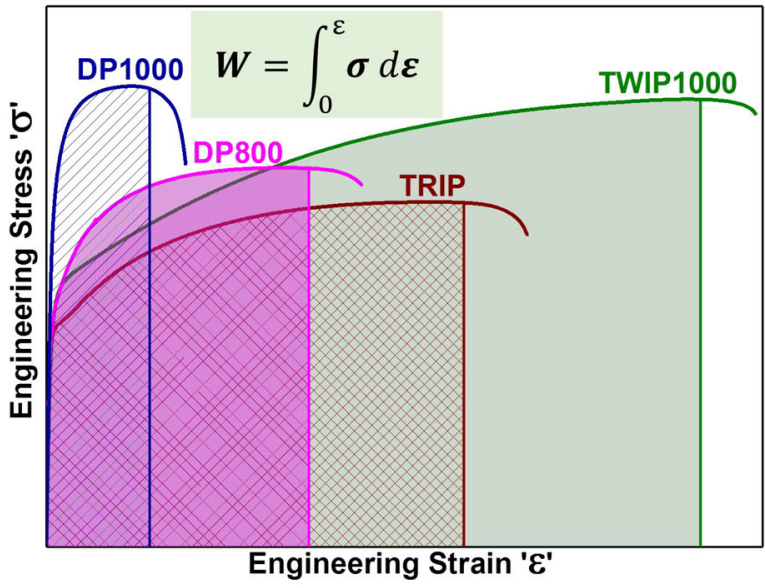

(c) Total mass specific energy absorption

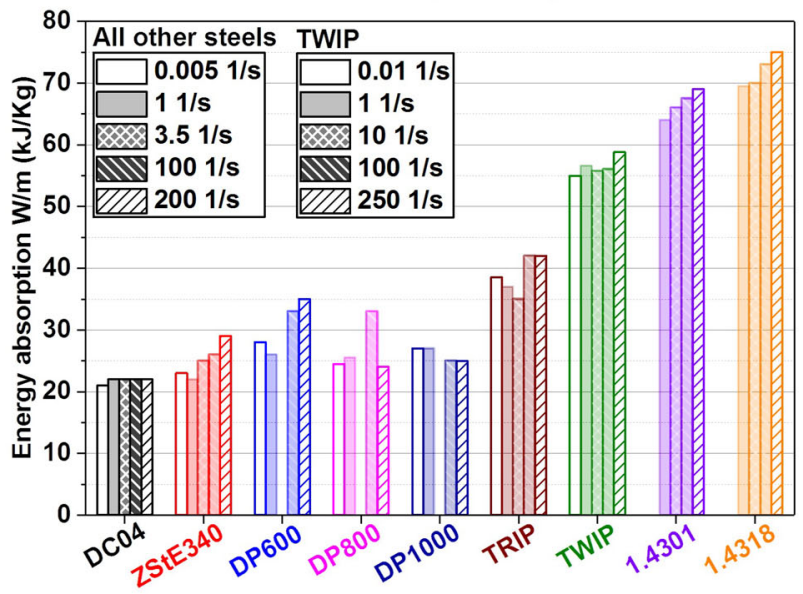

(b) Comparison of ECO-index

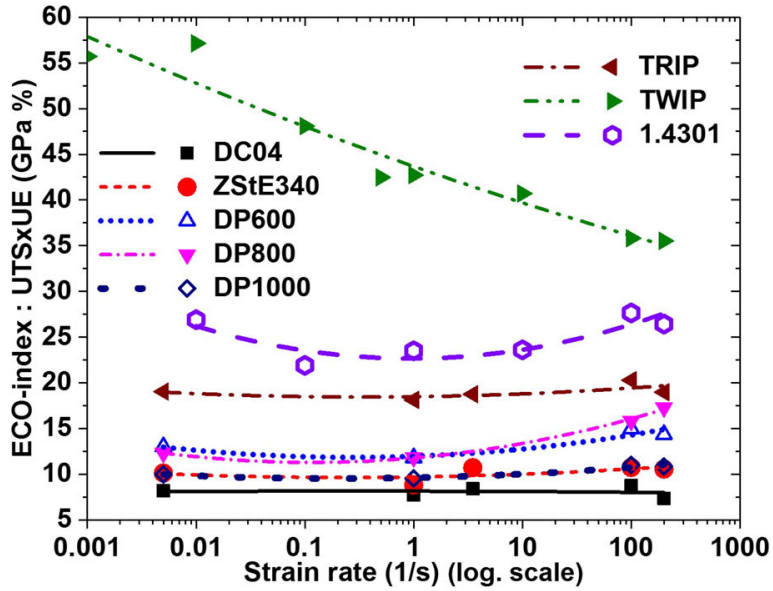

(d) Mass specific energy absorption until $10 \%$ elongation

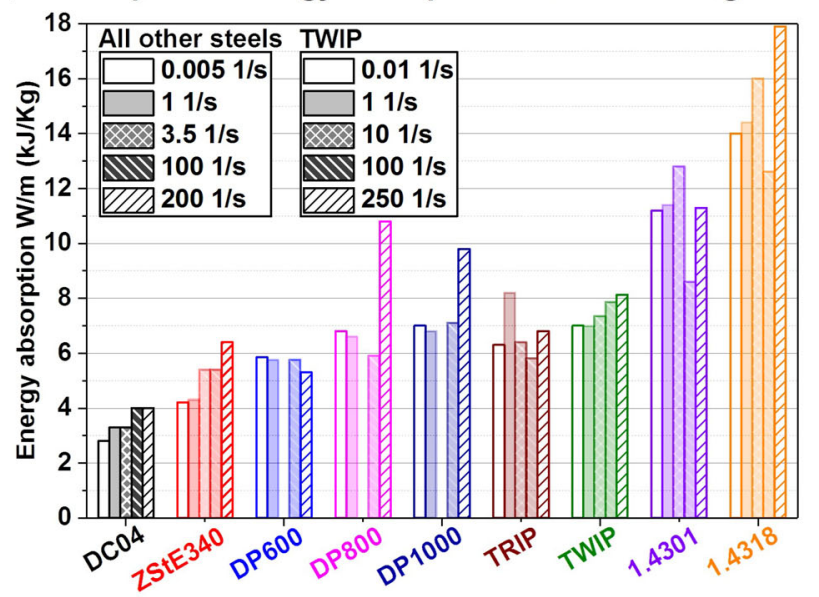

Fig. 6. Comparison of ECO-index and specific energy absorption capacity of TWIP steel with other AHSS and conventional steels. The mass specific energy absorption data for AHSS, ferritic and austenitic stainless steels were taken from Ref. 9. The strain rates used for TWIP steel are slightly different from other steels.

the ECO-index values are between $5 \leq$ ECO-index $\leq 25 \mathrm{GPa} \%$, which are half that of the damageresistant TWIP steel. TWIP steel has high tensile strength of about $1000 \mathrm{MPa}$, an ECO-index of above $35 \mathrm{GPa} \%$ and also excellent specific EA of about $55 \mathrm{~kJ} / \mathrm{kg}$ at all $\dot{\varepsilon}$ up to $250 / \mathrm{s}$, making it a highly suitable material for all automotive safety relevant parts subjected to both frontal and side crashes.

\section{DISCUSSION}

The measurement of temperature evolution during deformation is crucial for TWIP steel, since various temperature-dependent deformation mechanisms may be activated during straining at different strain rates. During a tensile test, a portion of the applied work is converted to heat during plastic deformation of the material. High strain rate tests can have test durations in the order of milliseconds to seconds, which do not allow sufficient amounts of time for heat diffusion from the interior of a sheet specimen to a free surface and subsequent transfer to the surroundings. Hence, adiabatic heating occurs in the material, which also depends on the sheet thickness. The larger sheet thickness leads to much higher increase of temperature. The temperature rise associated with the plastic deformation at different $\dot{\varepsilon}$ can have a significant softening effect on the flow stress, resulting in change in mechanical behavior.

The increase in temperature due to adiabatic heating at different $\dot{\varepsilon}$ at a point within the gage length for TWIP, TRIP and austenitic stainless steel is shown in Fig. 7c. It can be observed that for TWIP steel, the temperature increased beyond $180^{\circ} \mathrm{C}$ for all tests close to fracture. However, at about $30 \%$ strain, the temperature increase is between 60 and $100^{\circ} \mathrm{C}$. Such a large increase in temperature in the material results in the increase of SFE from $27 \mathrm{~mJ} /$ $\mathrm{m}^{2}$ to about $32-39 \mathrm{~mJ} / \mathrm{m}^{2}$. The variation of $\mathrm{SFE}$ with temperature for chemical composition shown in Table $\mathrm{I}$ is given in Fig. 7b. For the SFE below $40 \mathrm{~mJ} / \mathrm{m}^{2}$, mechanical twinning is the predominant deformation mode which occurs along with 
(a) Strain hardening behavior at different strain rates

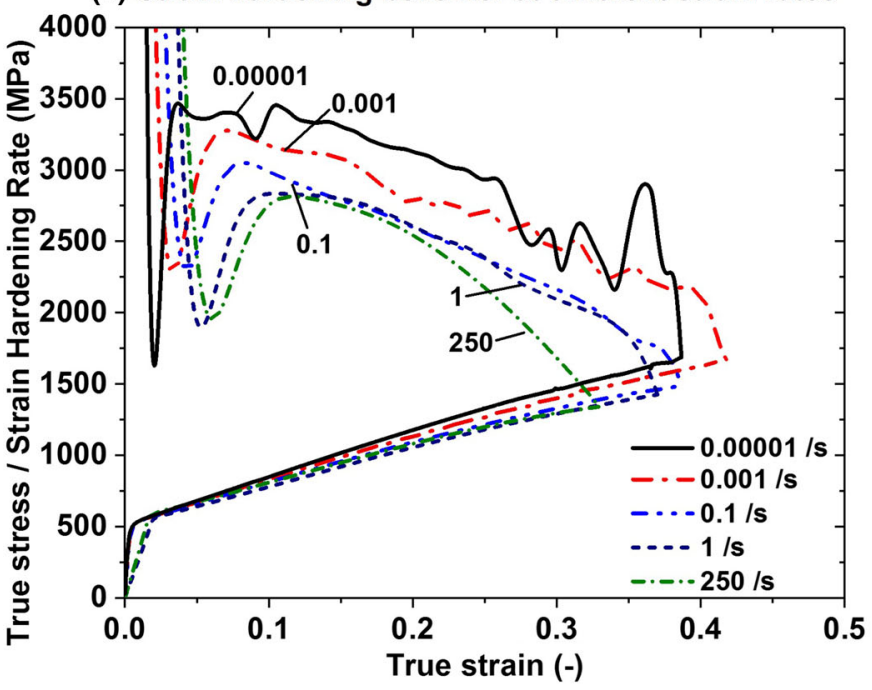

(b) Temperature influence on the SFE

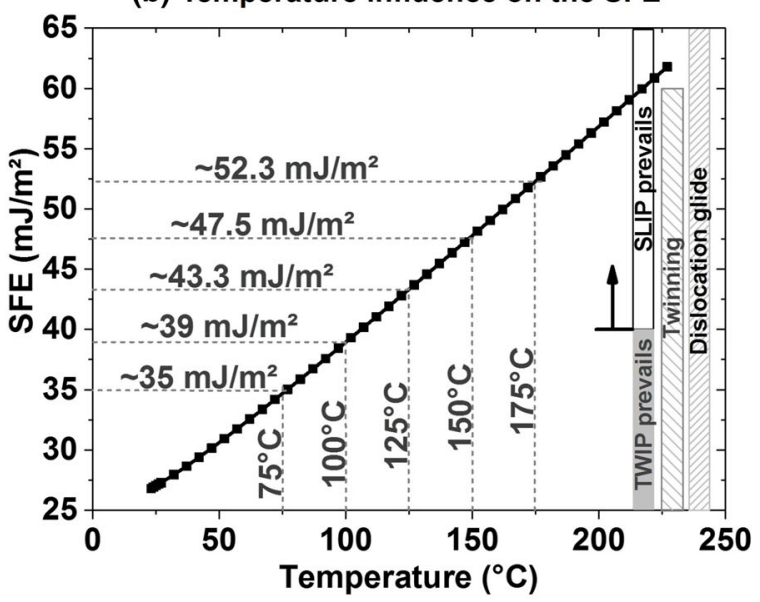

(c) Temperature increase due to adiabatic heating at a point within the gauge length and the SFE corresponding to the same temperature

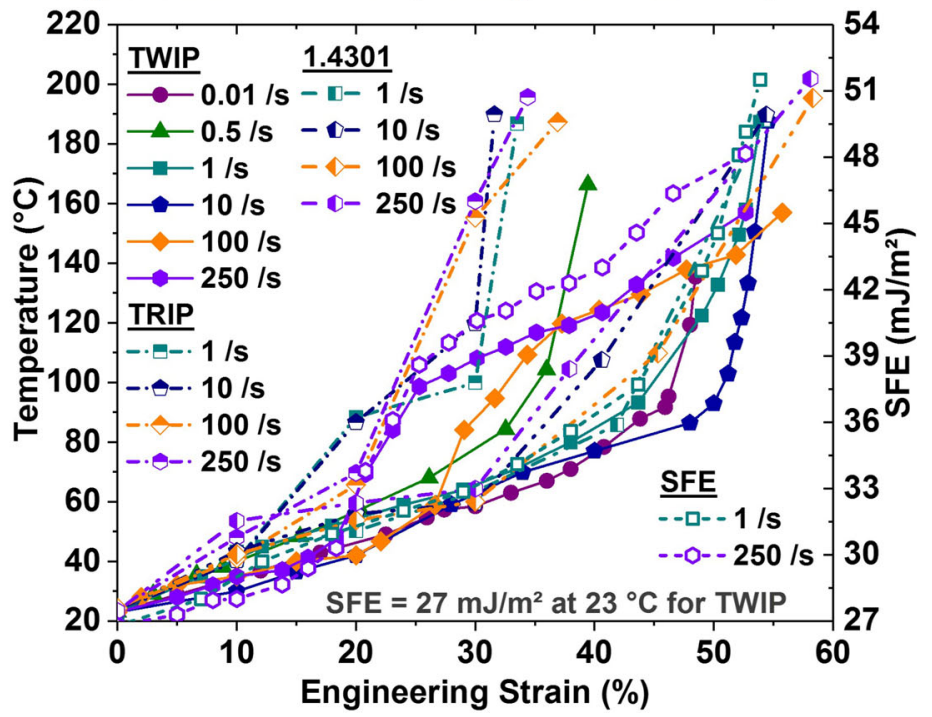

Fig. 7. Strain rate effect on work hardening and adiabatic heating. Stacking fault energy (SFE) was calculated for X60Mn22 alloy using the thermodynamic approach, as described in Ref. 12, assuming an interface energy $\left(\sigma^{\gamma / \varepsilon}\right)$ value of $10 \mathrm{~mJ} / \mathrm{m}^{2}$. The temperature increase due to adiabatic heating for TRIP steel and austenitic stainless steel 1.4301 are taken from Ref. 14.

dislocation glide; thereafter, dislocation slip becomes the most predominant deformation mode. Twinning still occurs for SFE up to $60 \mathrm{~mJ} / \mathrm{m}^{2}$, but dislocation slip becomes the most preferred deformation mode above $40 \mathrm{~mJ} / \mathrm{m}^{2} .{ }^{12}$ For $\dot{\varepsilon}$ of $0.01 / \mathrm{s}, 0.5 /$ $\mathrm{s}, 1 / \mathrm{s}$ and $10 / \mathrm{s}$, at about $30 \%$ strain, the temperature can increase to about $60^{\circ} \mathrm{C}$ from $\mathrm{RT}$, which corresponds to a SFE value of $32 \mathrm{~mJ} / \mathrm{m}^{2}$. This indicates that, with increasing macroscopic strain, the temperature rises due to adiabatic heating leading to an increase in SFE preferring deformation twinning. At very high $\dot{\varepsilon}$ of $100 / \mathrm{s}$ and $200 / \mathrm{s}$, at about $30 \%$ strain, the temperature can increase above $100^{\circ} \mathrm{C}$ from RT, which corresponds to a SFE value above $40 \mathrm{~mJ} / \mathrm{m}^{2}$. This large increase in SFE has led to change in the prevailing deformation mode from deformation twinning to dislocation glide.

The $\dot{\varepsilon}$ effect on the work-hardening behavior is shown in Fig. 7a. It can be observed that the SHR decreases with increasing $\dot{\varepsilon}$. Based on the detailed work described in Ref. 15, the SHR of fine-grained X60Mn22 TWIP steel can be divided into three distinct stages of hardening: (1) continuous decrease in the SHR, which involves dynamic recovery process such as cross-slip and annihilation of screw dislocations of opposite signs; (2) rapid increase in 
the SHR, implies that refinement of the mean free path by deformation twinning at strain level slightly higher than the onset of yielding; and (3) steady decrease in the SHR, ascribed to the reduced additional refinement of the dislocations and twin substructures, together with the increasing strengthening effect of the individual twins as obstacles to dislocation glide, reduce the capacity for trapping more dislocations leading to a decrease in SHR. With increasing $\dot{\varepsilon}$ from quasi-static to dynamic, the stage 1 of hardening has become wider and the initiation of stage 2 has shifted to larger strains. This could be mainly attributed to the change in twinning behavior.

The change in the rate of deformation could influence twin nucleation and twin density. The occurrence of DSA at lower $\dot{\varepsilon}$ in general results in locking of the partial dislocations leading to high dislocation density. ${ }^{16}$ The fine grain microstructure along with the high density of dislocations at grain boundaries (GB) result in higher stress concentration which could assist in nucleation of twins at GB. ${ }^{17}$ But this effect can be suppressed at high $\dot{\varepsilon}$ due to the suppression of DSA at high $\dot{\varepsilon}$. The experimental study by Ref. 18 showed that the number of twin nucleation sites per grain boundary area at lower $\dot{\varepsilon}$ is much larger compared to fewer twin nucleation sites at higher $\dot{\varepsilon}$. The thickness of individual twins increased from $10 \mathrm{~nm}$ at a $\dot{\varepsilon}$ of $0.0001 / \mathrm{s}$ to $40 \mathrm{~nm}$ at a $\dot{\varepsilon}$ of $10 / \mathrm{s}$, and individual twin spacing from $20 \mathrm{~nm}$ to $60 \mathrm{~nm}$. The study also found decrease in the twin area fraction with increasing $\dot{\varepsilon}$. This is mainly due to the increase in the average energy required for twin nucleation at high $\dot{\varepsilon}$, which led to suppressed twinning. ${ }^{18}$ This indicates differences in twin nucleation and growth behavior at quasi-static and dynamic loading. The synchrotron x-ray diffraction and transmission electron microscopy study by Ref. 19 at low and high $\dot{\varepsilon}$ stated that the dislocations and deformation twins are suppressed at high $\dot{\varepsilon}$ deformation, indicating negative strain rate sensitivity of work hardening. The detailed study by Ref. 20 also showed a decrease of twin volume fraction with increasing rate of deformation through electron channeling contrast imaging measurements and crystal plasticity simulations. This change in deformation behavior could be mainly attributed to adiabatic heating associated with high $\dot{\varepsilon}$ deformation. The increase of temperature at $\dot{\varepsilon}$ above $1 / \mathrm{s}$ lead to SFE increase above $40 \mathrm{~mJ} / \mathrm{m}^{2}$ favoring dislocation glide above $25 \%$ strain. Hence, in stage 3 of hardening, the SHR decreases more rapidly at higher $\dot{\varepsilon}$ compared to lower $\dot{\varepsilon}$. Higher temperature has decreased the work-hardening rate by increasing the rate of dynamic recovery and the suppression of deformation twinning due to the higher SFE. ${ }^{16}$

Similar to TWIP steel, the increase in $\dot{\varepsilon}$ led to significant rise in temperature due to adiabatic heating for TRIP steel and austenitic stainless steel 1.4301. The temperature rise in austenitic stainless steel is almost the same as that of TWIP steel at different strains, but in TRIP steel, the temperature rises above $60^{\circ} \mathrm{C}$ at about $20 \%$ elongation. By comparing adiabatic heating in three different steels at high $\dot{\varepsilon}$, it is clear that TWIP steel shows significantly different behavior compared to TRIP steel. To compare the effect of adiabatic heating, total mass specific EA and EA up to $10 \%$ elongation of TWIP steel is compared with different AHSS, ferritic and austenitic stainless steels at a $\dot{\varepsilon}$ of $100 / \mathrm{s}$ tested under similar conditions, as shown in Fig. 6c and $d$. It is evident that TWIP steel absorbs much more energy compared to AHSS and ferritic steels, but slightly less energy than austenitic stainless steels. Even for up to $10 \%$ elongation TWIP steel absorbs slightly more energy compared to DP1000. However, at a fixed elongation value of $10 \%$, EA values of ferritic steel ZStE340, DP600, DP800 and TRIP are about $6 \mathrm{~kJ} / \mathrm{kg}$, while DP1000 and TWIP1000 absorb marginally more energy, of about $7.5 \mathrm{~kJ} / \mathrm{kg}$ or $7.8 \mathrm{~kJ} / \mathrm{kg}$, while austenitic stainless steels absorb the highest energy of about $9 \mathrm{~kJ} / \mathrm{kg}$ (1.4301) to $13 \mathrm{~kJ} / \mathrm{kg}$ (1.4318). Among all the steels considered, ferritic steel DC04 absorbs the least amount of energy. Since the mechanical behavior of steels and the active deformation mechanisms vary largely with $\dot{\varepsilon}$, such comparisons are necessary for choosing TWIP steel for specific applications instead of others.

\section{CONCLUSION}

The X60Mn22 TWIP steel was investigated by uni-axial tensile tests under both quasi-static and dynamic conditions. For investigating the strain rate effect on the mechanical behavior, various in situ tensile testing methods were applied. The synchronous temperature measurements during deformation was monitored by carrying out tests in conjunction with a thermocamera. The main conclusions can be drawn for the investigated TWIP steel as follows:

- Strain-hardening rate of TWIP steel is extraordinarily high under both quasi-static and dynamic tests until maximum strain/failure. This can be attributed to the deformation by dislocation glide in combination with deformation twinning. A rise in temperature due to adiabatic heating has led to increases of SFE, thereby resulting in a change of twinning behavior or the promotion of dislocation glide under dynamic loading.

- Adiabatic heating has led to an increase in the temperature of the sample to about $35-50^{\circ} \mathrm{C}$ under quasi-static tests $(0.01-0.5 / \mathrm{s})$ up to $30 \%$ elongation, whereas under dynamic tests (1-250/ $\mathrm{s}$ ), it rose to about $85-100^{\circ} \mathrm{C}$ from room temperature $\left(23^{\circ} \mathrm{C}\right)$. At the point of fracture, the temperature increased beyond $100^{\circ} \mathrm{C}$ under quasi-static tests and $180^{\circ} \mathrm{C}$ under dynamic tests. The increase in temperature during defor- 
mation has led to an SFE increase from $27 \mathrm{~mJ} /$ $\mathrm{m}^{2}$ at $23^{\circ} \mathrm{C}$ to about $30-32 \mathrm{~mJ} / \mathrm{m}^{2}$ for a $\dot{\varepsilon}$ in the range from $0.01 / \mathrm{s}$ to $0.5 / \mathrm{s}$ and $38-40 \mathrm{~mJ} / \mathrm{m}^{2}$ for the $\dot{\varepsilon}$ above $10 / \mathrm{s}$. The SFE increase under quasistatic conditions has negligible effects on mechanical properties, whereas under dynamic loading, reduced strength and necking were observed.

- The strain rate has negligible effects on the yield and tensile strength, whereas the uniform and total elongation decreases under dynamic loading. The tensile strength of the material is above $1000 \mathrm{MPa}$ for all quasi-static $\dot{\varepsilon}$ and it decreases slightly when the $\dot{\varepsilon}$ increased to dynamic. Total elongation is above $50 \%$ for all $\dot{\varepsilon}$, whereas uniform elongation decreased mainly under dynamic loading due to necking and adiabatic heating.

- TWIP steel has excellent energy absorption capacity compared to other AHSS such as DP steels, TRIP steel and also ferritic steels. At all $\dot{\varepsilon}$ energy absorption of TWIP steel is above $55 \mathrm{~kJ} /$ $\mathrm{kg}$, which is almost double that of DP steel DP1000. However, the energy absorption of TWIP steel is slightly lower compared to austenitic stainless steels 1.4301 and 1.4318. TWIP steel has a very high ECO-index value of 52 $\mathrm{GPa} \%$ which decreases to about $35 \mathrm{GPa} \%$ under very high $\dot{\varepsilon}$ compared to the constant ECO-index values of AHSS which lie below $20 \mathrm{GPa} \%$ at all $\dot{\varepsilon}$.

\section{ACKNOWLEDGEMENTS}

The authors would like to acknowledge the financial support of the German Research Foundation (DFG) within the Collaborative Research Center SFB 761 "Steel-ab initio". The authors thank ThyssenKrupp Steel Europe AG for the material supply.

\section{REFERENCES}

1. C.D. Horvath, Advanced steels for lightweight automotive structures (Elsevier, 2010).

2. X. Sun (ed.), Failure mechanisms of advanced welding processes (Woodhead Pub. Ltd, 2010).

3. J.N. Hall and J.R. Fekete, Steels for auto bodies (Elsevier, 2017).

4. O. Grässel, L. Krüger, G. Frommeyer, and L. Meyer, International Journal of Plasticity 16(10-11), 1391 (2000).

5. O. Bouaziz, S. Allain, C. Scott, P. Cugy, and D. Barbier, Current Opinion in Solid State and Materials Science15(4), 141 (2011)

6. S.J. Lee, J. Han, S. Lee, S.H. Kang, S.M. Lee, and Y.K. Lee, Scientific Reports7(1), 3573 (2017).

7. B.C. De Cooman, Y. Estrin, and S.K. Kim, Acta Materialia142, 283 (2018).

8. C. Haase, T. Ingendahl, O. Gven, M. Bambach, W. Bleck, D.A. Molodov, and L.A. Barrales-Mora, Materials Science and Engineering: A649, 74 (2016).

9. W. Bleck and I. Schael, Steel Research 71(5), 173 (2000).

10. G. Huang, Y. Benda, H. Zhu, and J. Chintamani, The Strain Rate Effect on Tensile Properties and Fracture Strain of Advanced High Strength Steels (John Wiley \& Sons, 2011).

11. A. Saeed-Akbari, J. Imlau, U. Prahl, and W. Bleck, Metallurgical and Materials Transactions A40(13), 3076 (2009).

12. M. Madivala, A. Schwedt, S.L. Wong, F. Roters, U. Prahl, and W. Bleck, International Journal of Plasticity (2018).

13. L. Mosecker, D.T. Pierce, A. Schwedt, M. Beighmohamadi, J. Mayer, W. Bleck, and J.E. Wittig, Materials Science and Engineering: A642, 71 (2015).

14. K. Dahmen, Numerische Fließkurvenmodellierung von Feinblechstählen unter besonderer Berücksichtigung von Dehnrate, Temperatur und Phasenzusammensetzung. PhD thesis, RWTH Aachen University, Aachen (2014).

15. I. Gutierrez-Urrutia and D. Raabe, Scripta Materialia66(12), 992 (2012).

16. I.C. Jung and B.C. De Cooman, Acta Materialia61(18), 6724 (2013).

17. H. Gwon, J.K. Kim, S. Shin, L. Cho, and B.C. De Cooman, Materials Science and Engineering: A696, 416 (2017).

18. H.K. Yang, Z.J. Zhang, Y.Z. Tian, and Z.F. Zhang, Materials Science and Engineering: A690, 146 (2017).

19. Z.Y. Liang, X. Wang, W. Huang, and M.X. Huang, Acta Materialia88, 170 (2015).

20. D.R. Steinmetz, T. Jäpel, B. Wietbrock, P. Eisenlohr, I. Gutierrez-Urrutia, A. Saeed-Akbari, T. Hickel, F. Roters, and D. Raabe, Acta Materialia61(2), 494 (2013). 